\title{
Resección laparoscópica de divertículo esofágico epifrénico secundario a acalasia*
}

\author{
Drs. JAIME ZAMARÍN M. ${ }^{1}$, CARLOS GARCÍA C. ${ }^{1}$, CRISTIAN GALLARDO M. ${ }^{1}$, MARCO CERONI V. ${ }^{1}$ \\ 1 Servicio de Cirugía Hospital Clínico San Borja Arriarán. \\ Santiago, Chile.
}

\section{Laparoscopic management of a epiphrenic diverticulum associated with symptomatic achalasia}

Paciente de sexo femenino de 43 años, con historia de dos años de disfagia lógica y baja de peso. El estudio endoscópico reveló estenosis concéntrica de esófago inferior, asociado a divertículo a $40 \mathrm{~cm}$ de arcada dentaria. El estudio radiológico se presenta en Figura 1. La manometría demostró severa alteración de motilidad del cuerpo esofágico e imposibilidad de franquear esfínter esofágico inferior, sugerente de Acalasia. Se abordó vía laparoscópica, realizándose diverticulectomía esofágica con stappler lineal (Figura 2), cardiomiotomía de Heller y fonduplicatura anterior. La paciente evolucionó sin complicaciones, con resolución de los síntomas preoperatorios. El control radiológico se ilustra en Figura 3.

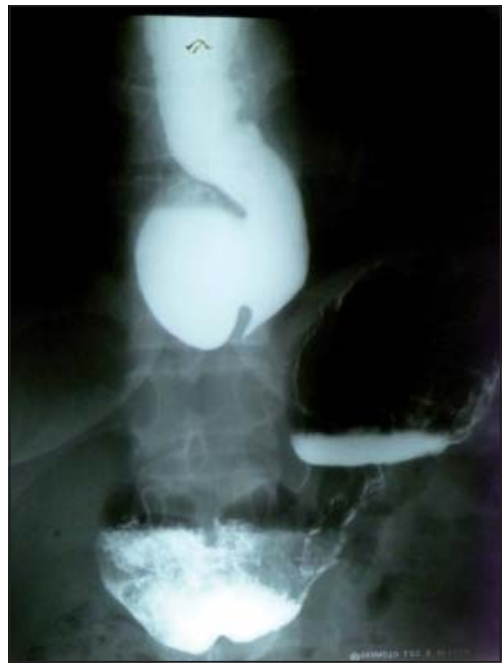

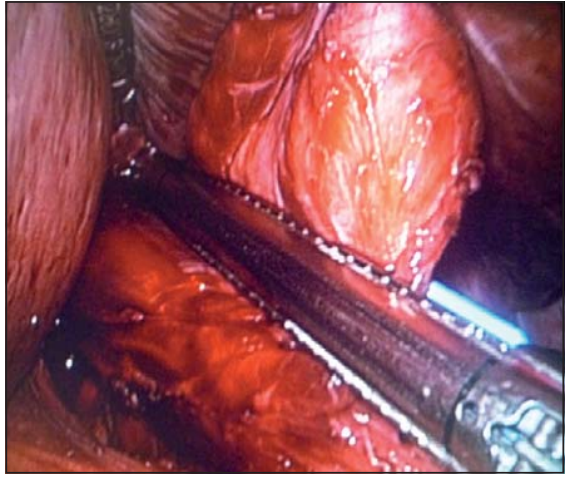

Figura 2. Diverticulectomía.

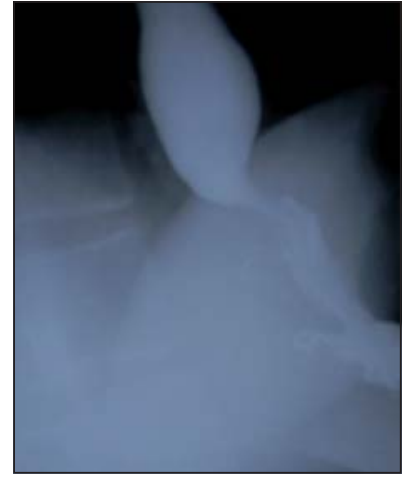

Figura 3. Control radiológico.

Figura 1. Divertículo epifrénico.

*Recibido el 12 de mayo de 2011 y aceptado para publicación el 11 de junio de 2011.

Correspondencia: Dr. Jaime Zamarín M.

Santa Rosa 1234, Santiago, Chile. jaimezamarin@hotmail.com 


\section{Referencias}

1. Melman L, Quinlan J. Esophageal manometric characteristics and outcomes for laparoscopic esophageal diverticulectomy, myotomy, and partial fundoplication for epiphrenic diverticula. Surg Endosc. 2009;23:1337-41.
2. Fraiji E, Bloomston M, Carey L. Laparoscopic management of symptomatic achalasia associated with epiphrenic diverticulum. Surg Endos. 2003;17:1600-3.

3. Benacci JC, Deschamps C, Trastek VF. Epiphrenic diverticulum: results of surgical treatment. Ann Thorac Surg. 1993;55:1109-14. 